\title{
Effects of a pharmaceutical care model on medication adherence and glycemic control of people with type 2 diabetes
}

This article was published in the following Dove Press journal:

Patient Preference and Adherence

4 September 2014

Number of times this article has been viewed

\author{
Wen Wei Chung ${ }^{1,2}$ \\ Siew Siang Chua' \\ Pauline Siew Mei Lai ${ }^{3}$ \\ Siew Pheng Chan ${ }^{4}$ \\ 'Department of Pharmacy, Faculty \\ of Medicine, University of Malaya, \\ Kuala Lumpur, Malaysia; ${ }^{2}$ harmacy \\ Department, University Malaya \\ Medical Centre, Kuala Lumpur, \\ Malaysia; ${ }^{3}$ Department of Primary \\ Care Medicine, University \\ Malaya Primary Care Research \\ Group, ${ }^{4}$ Department of Medicine, \\ Faculty of Medicine, University \\ of Malaya, Kuala Lumpur, Malaysia
}

Correspondence: Siew Siang Chua Department of Pharmacy, Faculty of Medicine, University of Malaya, 50603 Kuala Lumpur, Malaysia

Tel +60379676688

Fax +60379674964

Email chuass@um.edu.my
Background: Diabetes mellitus is a lifelong chronic condition that requires self-management. Lifestyle modification and adherence to antidiabetes medications are the major determinants of therapeutic success in the management of diabetes.

Purpose: To assess the effects of a pharmaceutical care (PC) model on medication adherence and glycemic levels of people with type 2 diabetes mellitus.

Patients and methods: A total of 241 people with type 2 diabetes were recruited from a major teaching hospital in Malaysia and allocated at random to the control $(n=121)$ or intervention $(n=120)$ groups. Participants in the intervention group received PC from an experienced pharmacist, whereas those in the control group were provided the standard pharmacy service. Medication adherence was assessed using the Malaysian Medication Adherence Scale, and glycemic levels (glycated hemoglobin values and fasting blood glucose [FBG]) of participants were obtained at baseline and after 4, 8, and 12 months.

Results: At baseline, there were no significant differences in demographic data, medication adherence, and glycemic levels between participants in the control and intervention groups. However, statistically significant differences in FBG and glycated hemoglobin values were observed between the control and intervention groups at months 4, 8, and 12 after the provision of PC (median FBG, 9.0 versus $7.2 \mathrm{mmol} / \mathrm{L}[P<0.001]$; median glycated hemoglobin level, $9.1 \%$ versus $8.0 \%[P<0.001]$ at 12 months). Medication adherence was also significantly associated with the provision of $\mathrm{PC}$, with a higher proportion in the intervention group than in the control group achieving it $(75.0 \%$ versus $58.7 \% ; P=0.007)$.

Conclusion: The provision of $\mathrm{PC}$ has positive effects on medication adherence as well as the glycemic control of people with type 2 diabetes. Therefore, the PC model used in this study should be duplicated in other health care settings for the benefit of more patients with type 2 diabetes.

Keywords: pharmaceutical care, medication adherence, glycemic control, type 2 diabetes mellitus

\section{Introduction}

The International Diabetes Foundation predicted that by 2025, the Southeast Asia Region would have the highest prevalence of diabetes. ${ }^{1,2}$ In Malaysia, the Third National Health Morbidity Survey reported a drastic increase in the prevalence of diabetes, from $8.3 \%$ to $14.9 \%$, among Malaysians aged 30 years and older within a 10-year period (1996-2006). ${ }^{3}$ The World Health Organization estimated that by 2030, Malaysia would have a total of 2.48 million individuals diagnosed with diabetes; ${ }^{3}$ however, this figure has already been surpassed, as in 2011, 2.6 million Malaysians had been diagnosed with diabetes. ${ }^{2,4}$ This increase in diabetes is a major concern, as 
the morbidity of people with diabetes is 11 times higher than the general population. ${ }^{5}$

Diabetes mellitus is a lifelong chronic condition that requires self-management by individuals. Lifestyle modification and adherence to antidiabetes medications are the major determinants of therapeutic success in the management of diabetes. ${ }^{6}$ Studies demonstrate that poor glycemic control results in the development of long-term complications and was also associated with disease progression, hospitalization, premature disability, and mortality. ${ }^{7-9}$ A study conducted in Malaysia found that $58 \%$ of people with diabetes had neuropathy, 53\% had retinopathy, $8.6 \%$ had cardiovascular diseases, $5.6 \%$ had stroke, and $1.9 \%$ had amputation. ${ }^{10}$

In addition, other studies have found a significant association between adherence to antidiabetes medications and glycemic control. ${ }^{11-17}$ A study conducted in Malaysia found that $41.7 \%$ of people with diabetes did not adhere to their antidiabetes medications and that the odds of achieving glycemic control were two times higher among those who adhered to their antidiabetes medications compared with those who did not. ${ }^{18}$ Another study also concluded that those who were nonadherent to their medications had significantly higher levels of fasting blood glucose. ${ }^{19,20}$

The roles of pharmacists within the health care system today have evolved from a product-centered approach to patient-centered care, which means the refocusing of time and energy on professional responsibilities. ${ }^{20-23}$ Therefore, the fundamental goal of pharmacy practice today is to provide pharmaceutical care (PC). ${ }^{24} \mathrm{PC}$ is the responsible provision of drug therapy via collaboration of a clinical pharmacist with the patient, as well as other members of the health care team, in designing, implementing, and monitoring a therapeutic plan that will produce specific outcomes. This includes identifying potential and actual drug-related problems, resolving current drug-related problems, and preventing future drug-related problems. ${ }^{25}$

Studies on the effects of PC in the management of diabetes observed a statistically significant reduction in glycated hemoglobin $\left(\mathrm{HbA}_{1 \mathrm{c}}\right)$ levels in the intervention group. ${ }^{11,26-34}$ However, most of the studies in the literature were conducted in countries such as the United States, the United Kingdom, and Australia. ${ }^{11,26-34}$

The hypothesis is that although the provision of $\mathrm{PC}$ in Malaysia has increased gradually over the last 2 decades, a majority of pharmacists in Malaysia are still not intensively involved in patient care, and hence, such service is deemed to have a greater effect in Malaysia than in the developed countries, where the roles of pharmacists in patient care are already well-established. In addition, such studies are still scarce in developing countries such as Malaysia, and thus far, there is only one qualitative study that has been published with regard to PC. ${ }^{35}$ Therefore, the present study is warranted to investigate the effects of a PC model on medication adherence and glycemic levels of people with type 2 diabetes (T2DM).

\section{Methods}

This is a prospective randomized controlled trial. The study was approved by the Medical Ethics Committee of the major teaching hospital involved in the study (MEC 757.112). Written, informed consent was obtained from all the participants on recruitment into this study.

\section{Participants}

People who had been diagnosed with T2DM who were aged 21 years and older but were younger than 75 years, were taking at least one antidiabetes medication, were able to communicate in English, and had an $\mathrm{HbA}_{1 \mathrm{c}}$ level of $8 \%$ and above, could be included in this study. Any person with T2DM who visited the diabetes clinic of a major teaching hospital during the recruitment period and who fulfilled the inclusion criteria was requested to participate in this study. Participants' fasting blood glucose (FBG) levels and $\mathrm{HbA}_{1 \mathrm{c}}$ values were obtained from their medical records.

Participants' demographic and medical characteristics were collected via face-to-face interview and confirmed with participants' medical records. Medication adherence of participants was assessed using the validated Malaysian Medication Adherence Scale (MALMAS). ${ }^{36}$ MALMAS was developed and scored according to the Morisky Medication Adherence scale, ${ }^{37,38}$ on which the total score ranged from 0-8. Medication adherence was classified into three levels on the basis of the total scores obtained: low adherence (total score, <6), medium adherence (total score, 6-7.9), and high adherence (total score, 8 ). In addition, medication adherence was classified into medication adherence (total score, 6-8) and nonadherence (total score, $<6$ ). ${ }^{36}$

\section{Procedure}

Participants were allocated at random to the control or intervention groups. Participants in the intervention group received $\mathrm{PC}$ from a pharmacist, whereas those in the control group were provided standard pharmacy services, which consisted of dispensing the medications and providing brief instructions on how to take them. A pharmacist reviewed the medications of those in the intervention group and tried to 
resolve any drug-related problems encountered by the participants. In addition, participants in the intervention group were educated on diabetes, hypertension, and hyperlipidemia, as well as all aspects of their medications, with an emphasis on the importance of medication adherence. The intervention group was also given and taught how to use a pill box and a blood glucose meter to conduct self-monitoring of blood glucose at home and to record their readings. Participants in the intervention group received monthly follow-up telephone calls to help participants resolve any pharmaceutical care issues or drug-related problems.

All participants from both control and intervention groups were asked to return to the pharmacy for their next visit, which should preferably be about 3-4 months from the date of recruitment. Participants from both groups had their blood samples taken by a nurse and tested for FBG and $\mathrm{HbA}_{1 \mathrm{c}}$ levels by a certified clinical laboratory of the teaching hospital about a week before their next appointment for the study. Participants from the intervention group were counseled by a pharmacist regarding their blood glucose levels. If the participants did not have their blood glucose levels under control, then more stringent measures would be recommended after discussion with the participants' clinicians. Data were collected at recruitment (baseline) and then at 4,8 , and 12 months after recruitment. All interventions were conducted in accordance with a PC counseling and education checklist. Each intervention took approximately an hour at baseline, whereas subsequent visits took approximately half an hour for the pharmacist to provide counseling and education to each intervention participant.

In line with the UK Prospective Diabetes Study, a 1\% reduction in $\mathrm{HbA}_{1 \mathrm{c}}$ level reduces the risk for myocardial infarction by $14 \%$, that for microvascular complications by $37 \%$, and that for diabetes-related deaths by $21 \% .^{39,40}$ Therefore, the present study would be deemed successful if a reduction of at least $1 \%$ in $\mathrm{HbA}_{1 \mathrm{c}}$ value could be achieved.

\section{Statistical analysis}

All data were analyzed using PASW Statistics for Windows, version 18 (SPSS Inc., Chicago, IL, USA). Associations between categorical variables were analyzed using Pearson chi-square tests, whereas differences in clinical outcome measures (continuous variables) between the control and intervention groups were evaluated using independent $t$-test or Mann-Whitney $U$-test. Differences between baseline and endpoint outcome measures were determined using the paired $t$-test or Wilcoxon signed-rank test. The Generalized Estimating Equations (GEE) was used to analyze the predictors of the study outcomes, $\mathrm{HbA}_{1 \mathrm{c}}$, and medication adherence. Various parameters (such as participant's age, sex, ethnic group, education level, working status, income group, marital status, levels of exercise, body mass index [BMI] status, duration of diagnosis with diabetes, number of concurrent diseases, total number of prescribed medications, and whether in the control or intervention group) that may be associated with the study outcomes were included in the GEE analysis. Any $P$-value less than 0.05 was considered statistically significant.

\section{Results}

A total of 241 participants were recruited for this study. The demographic and medical data of the participants are as shown in Table 1. The thresholds for income groups were classified according to a household income survey conducted in Malaysia. ${ }^{41}$ In this survey, the middleclass income group was considered as from RM1,001 to RM5,000 per month. Therefore, in the present study, the middle-class group was divided into a lower middle-class income group (RM1,001-RM3,000) and an upper middleclass income group (RM3,001-RM5,000). The BMI of participants was categorized using international thresholds: healthy, $18.5-24.9 \mathrm{~kg} / \mathrm{m}^{2}$; overweight, $25-29.9 \mathrm{~kg} / \mathrm{m}^{2}$; and obese, $30 \mathrm{~kg} / \mathrm{m}^{2}$ and above. ${ }^{42}$ The BMI of both control and intervention groups also did not show any significant difference at baseline. Table 1 shows a much higher proportion of participants with diploma and tertiary education in the intervention group compared with in the control group (42.5\% vs $27.2 \%$ ), although it was not statistically significant. Using the GEE analysis, it was found that education levels were not significantly related to medication adherence or $\mathrm{HbA}_{1 \mathrm{c}}$.

Medication adherence of participants was assessed using the MALMAS (Table 2). Glycemic levels of participants are represented by $\mathrm{FBG}$ and $\mathrm{HbA}_{1 \mathrm{c}}$ (Figures 1 and 2). Using the Kolmogorov-Smirnov test, the $P$-values for all domains were less than 0.001 , which implied that the data did not fulfil the normal distribution criteria. At baseline, there were no significant differences in demographic data and other characteristics, medication adherence, or glycemic levels between participants in the control and intervention groups (Tables 1 and 2; Figures 1 and 2).

\section{Medication adherence}

Whether medication adherence was categorized into three (high, medium, and low adherence) or two (high or medium adherence, which are considered as adherent to medication, 
Table I Characteristics of participants

\begin{tabular}{|c|c|c|c|c|}
\hline \multirow{2}{*}{$\begin{array}{l}\text { Demographic data } \\
(\mathrm{N}=\mathbf{2 4} \text { I) }\end{array}$} & \multicolumn{2}{|l|}{ Frequency (\%) } & \multirow[t]{2}{*}{$\chi^{2}$ (P-value) } & \multirow{2}{*}{$\begin{array}{l}\text { z value } \# \\
\text { (P-value) }\end{array}$} \\
\hline & $\begin{array}{l}\text { Control } \\
(n=121)\end{array}$ & $\begin{array}{l}\text { Intervention } \\
(n=\mid 20)\end{array}$ & & \\
\hline \multicolumn{5}{|l|}{ Sex } \\
\hline Male & $56(46.3 \%)$ & $50(41.7 \%)$ & $0.52 I(0.47 I)$ & \\
\hline Female & $65(53.7 \%)$ & $70(58.3 \%)$ & & \\
\hline Age in years, mean $\pm S D$ (median) & $58.5 \pm 8.3(59.0)$ & $59.7 \pm 9.5(59.5)$ & & $-1.132(0.258)$ \\
\hline $21-50$ & $20(16.5 \%)$ & $17(14.2 \%)$ & I.505 (0.47I) & \\
\hline $5 I-60$ & $53(43.8 \%)$ & $46(38.3 \%)$ & & \\
\hline $61-75$ & $48(39.7 \%)$ & 57 (47.5\%) & & \\
\hline \multicolumn{5}{|l|}{ Ethnic group } \\
\hline Malay & 47 (38.8\%) & $6 \mathrm{I}(50.8 \%)$ & $4.830(0.089)^{@}$ & \\
\hline Chinese & $23(19.0 \%)$ & $26(21.7 \%)$ & & \\
\hline Indian & $47(38.8 \%)$ & $32(26.7 \%)$ & & \\
\hline Others & $4(3.3 \%)$ & $\mathrm{I}(0.8 \%)$ & & \\
\hline \multicolumn{5}{|l|}{ Marital Status } \\
\hline Single & $4(3.3 \%)$ & $4(3.3 \%)$ & $3.089(0.378)$ & \\
\hline Married & $97(80.2 \%)$ & $98(81.7 \%)$ & & \\
\hline Divorced & $7(5.8 \%)$ & $2(1.7 \%)$ & & \\
\hline Widower & $13(10.7 \%)$ & $16(13.3 \%)$ & & \\
\hline \multicolumn{5}{|l|}{ Level of education } \\
\hline None and primary & $13(10.7 \%)$ & $8(6.7 \%)$ & $6.637(0.084)$ & \\
\hline Secondary & $75(62.0 \%)$ & $61(50.8 \%)$ & & \\
\hline Diploma & $16(13.2 \%)$ & $27(22.5 \%)$ & & \\
\hline Tertiary and postgraduate & $17(14.0 \%)$ & $24(20.0 \%)$ & & \\
\hline \multicolumn{5}{|l|}{ Working status } \\
\hline Yes & $50(41.3 \%)$ & $48(40.0 \%)$ & $0.044(0.834)$ & \\
\hline No & $71(58.7 \%)$ & $72(60.0 \%)$ & & \\
\hline \multicolumn{5}{|l|}{ Income per month } \\
\hline$\leq \mathrm{RMI}, 000(\mathrm{USD} \$ 309)$ & $48(39.7 \%)$ & 49 (40.8\%) & $6.826(0.234)$ & \\
\hline RMI,00I-3,000 (USD\$3I0-\$929) & $45(37.2 \%)$ & 47 (39.2\%) & & \\
\hline RM3,00I-5,000 (USD $\$ 930-\$ 1,548)$ & $24(19.8 \%)$ & $14(11.7 \%)$ & & \\
\hline$\geq$ RM5,00I (USD $\$ 1,549)$ & $4(3.3 \%)$ & $10(8.3 \%)$ & & \\
\hline Body mass index in kg/m@@, mean $\pm \mathrm{SD}$ (median) & $29.1 \pm 7.0(28.4)$ & $29.3 \pm 6.3(28.0)$ & & $-0.288(0.773)$ \\
\hline Underweight to healthy weight & $27(23.5)$ & $21(18.4)$ & $1.917(0.383)$ & \\
\hline Overweight & $44(38.3)$ & $58(50.9)$ & & \\
\hline Obese & $44(38.3)$ & $35(30.7)$ & & \\
\hline \multicolumn{5}{|l|}{ Number of times patient exercises in a week } \\
\hline$\leq$ Once a week & $43(35.5 \%)$ & $35(29.2 \%)$ & $2.208(0.331)$ & \\
\hline Twice a week & $10(8.3 \%)$ & $16(13.3 \%)$ & & \\
\hline$\geq$ Three times a week & $68(56.2 \%)$ & $69(57.5 \%)$ & & \\
\hline Duration of diabetes in years, mean \pm SD (median) & $16.3 \pm 8.0(15.0)$ & $16.3 \pm 8.0(15.0)$ & & $-0.112(0.911)$ \\
\hline $0-10$ years & $28(23.1 \%)$ & $30(25.0 \%)$ & $0.623(0.732)$ & \\
\hline $\mathrm{II}-20$ years & $52(43.0 \%)$ & $55(45.8 \%)$ & & \\
\hline$>20$ years & $4 \mathrm{I}(33.9 \%)$ & 35 (29.2\%) & & \\
\hline \multicolumn{5}{|l|}{ Number of concurrent diseases } \\
\hline 0 & $38(31.4 \%)$ & $30(25.0 \%)$ & $2.578(0.765)$ & \\
\hline 1 & $31(25.6 \%)$ & $4 \mathrm{I}(34.2 \%)$ & & \\
\hline 2 & $34(28.1 \%)$ & $33(29.5 \%)$ & & \\
\hline$>3$ & $18(14.9 \%)$ & $16(13.3 \%)$ & & \\
\hline Number of prescribed medications, mean \pm SD (median) & $6.1 \pm 2.2(6.0)$ & $6.4 \pm 2.1(6.0)$ & & $-0.247(0.805)$ \\
\hline $0-5$ types & 47 (38.8\%) & $4 \mathrm{I}(34.2 \%)$ & $0.568(0.45 \mathrm{I})$ & \\
\hline$\geq 6$ types & $74(61.2 \%)$ & 79 (65.8\%) & & \\
\hline \multicolumn{5}{|l|}{ Medications prescribed at baseline } \\
\hline Alpha-glucosidase inhibitor & $9(3.5 \%)$ & 17 (6.7\%) & $0.287^{\wedge}(0.866)$ & \\
\hline Biguanide & $108(41.9 \%)$ & $105(41.2 \%)$ & & \\
\hline Dipeptidyl peptidase-4 inihibitor & $2(0.8 \%)$ & $0(0 \%)$ & & \\
\hline Meglitinide & I (0.4\%) & $0(0 \%)$ & & \\
\hline
\end{tabular}


Table I (Continued)

\begin{tabular}{|c|c|c|c|c|}
\hline \multirow{2}{*}{$\begin{array}{l}\text { Demographic data } \\
(\mathrm{N}=\mathbf{2 4} \text { I) }\end{array}$} & \multicolumn{2}{|c|}{ Frequency (\%) } & \multirow[t]{2}{*}{$\chi^{2}$ (P-value) } & \multirow{2}{*}{$\begin{array}{l}\text { v value }^{\#} \\
(P \text {-value })\end{array}$} \\
\hline & $\begin{array}{l}\text { Control } \\
(n=121)\end{array}$ & $\begin{array}{l}\text { Intervention } \\
(n=\mid 20)\end{array}$ & & \\
\hline \multicolumn{5}{|l|}{ Medications prescribed at baseline } \\
\hline Sulphonylurea & $39(15.1 \%)$ & $36(14.1 \%)$ & & \\
\hline Thiazolidinedione & $3(1.2 \%)$ & $2(0.8 \%)$ & & \\
\hline Insulin & $96(37.2 \%)$ & 95 (37.3\%) & & \\
\hline Incretin mimetic & $0(0 \%)$ & $0(0 \%)$ & & \\
\hline \multicolumn{5}{|c|}{ Medications prescribed at the twelfth month } \\
\hline Alpha-glucosidase inhibitor & $3(1.2 \%)$ & II (4.5\%) & $2.024^{\wedge}(0.567)$ & \\
\hline Biguanide & $103(41.9 \%)$ & $94(38.5 \%)$ & & \\
\hline Dipeptidyl peptidase-4 inhibitor & $6(2.4 \%)$ & $7(2.9 \%)$ & & \\
\hline Meglitinide & $0(0 \%)$ & $0(0 \% 0$ & & \\
\hline Sulphonylurea & $32(13.0 \%)$ & 35 (I4.3\%) & & \\
\hline Thiazolidinedione & I (0.4\%) & $0(0 \%)$ & & \\
\hline Insulin & $100(40.7 \%)$ & 95 (38.9\%) & & \\
\hline Incretin mimetic & I (0.4\%) & $2(0.8 \%)$ & & \\
\hline
\end{tabular}

Notes: \#Mann-Whitney U-test is used for continuous variables; $\chi^{2}$, chi-square test used for categorical variables; @ chi-square value was obtained by omitting the ethnic group "Others"; @@ealthy weight range, $18.5-24.9 \mathrm{~kg} / \mathrm{m}^{2}$; overweight, $25-29.9 \mathrm{~kg} / \mathrm{m}^{2}$; obese, $\geq 30 \mathrm{~kg} / \mathrm{m}^{2} ; \wedge^{\wedge}$ chi-square value was obtained by analyzing the major classes of antidiabetes agents (biguanide, sulfonylurea, and insulin), as the sample size for the other classes was very small.

Abbreviation: $\mathrm{N}$, total participants in the study; $\mathrm{n}$, number of participants in each group; SD, standard deviation.

and low adherence, which is considered as nonadherence to medication) levels, ${ }^{36}$ there were significant associations between the levels of adherence and the provision of PC at months 4, 8, and 12 (Tables 2 and 3).

\section{Outcomes of glycemic levels (FBG and $\mathrm{HbA}_{1 \mathrm{c}}$ )}

Statistically significant differences in $\mathrm{FBG}$ and $\mathrm{HbA}_{1 \mathrm{c}}$ were observed between the control and intervention groups at

Table 2 Comparison of medication adherence between control and intervention groups based on three levels of adherence

\begin{tabular}{llll}
\hline Medication & \multicolumn{2}{l}{ Frequency (\%) } & \multirow{2}{*}{$\chi^{2}$ (P-value) } \\
\cline { 2 - 3 } adherence & Control & Intervention & \\
\hline Baseline & $\mathrm{n}=121$ & $\mathrm{n}=120$ & $1.900(0.387)$ \\
Low adherence & $43(35.5 \%)$ & $36(30.0 \%)$ & \\
Medium adherence & $43(35.5 \%)$ & $53(44.2 \%)$ & \\
High adherence & $35(28.9 \%)$ & $31(25.8 \%)$ & \\
Month 4 & $\mathrm{n}=109$ & $\mathrm{n}=115$ & \multirow{2}{*}{$7.310(0.026)^{*}$} \\
Low adherence & $48(44.0 \%)$ & $31(27.0 \%)$ & \\
Medium adherence & $35(32.1 \%)$ & $52(44.3 \%)$ & \\
High adherence & $26(23.9 \%)$ & $33(28.7 \%)$ & \\
Month 8 & $\mathrm{n}=110$ & $\mathrm{n}=102$ & \multirow{2}{*}{$7.289(0.026)^{*}$} \\
Low adherence & $46(41.8 \%)$ & $25(24.5 \%)$ & \\
Medium adherence & $33(30.0 \%)$ & $37(36.3 \%)$ & \\
High adherence & $31(28.2 \%)$ & $40(39.2 \%)$ & \multirow{2}{*}{$8.182(0.017)^{*}$} \\
Month I2 & $\mathrm{n}=121$ & $\mathrm{n}=120$ & \\
Low adherence & $50(41.3 \%)$ & $30(25.0 \%)$ & \\
Medium adherence & $41(33.9 \%)$ & $45(37.5 \%)$ & \\
High adherence & $30(24.8 \%)$ & $45(37.5 \%)$ & \\
\hline
\end{tabular}

Notes: *Statistically significant at $P<0.05 . \chi^{2}$, chi-square test. Abbreviations: $\mathrm{n}$, total number of participants in each group.
4 months after intervention, and these continued until the end of the study period (12 months; Figures 1 and 2). In addition, FBG and $\mathrm{HbA}_{1 \mathrm{c}}$ showed a statistically significant reduction from recruitment until the end of the study period (12 months after the provision of PC) for the intervention group, whereas the control group did not have any significant changes (Table 4). At the end of the 12-month study period, there were significant differences between the percentage of the control and intervention groups who achieved FBG less than $6.2 \mathrm{mmol} / \mathrm{L}$ and $\mathrm{HbA}_{1 \mathrm{c}}$ levels less than $8 \%$ (FBG, $18.2 \%$ versus $31.7 \%$ [chi-square, $5.859 ; P=0.015$ ]; $\mathrm{HbA}_{1 \mathrm{c}}, 22.3 \%$ versus $47.5 \%$ [chi-square, 16.831; $P<0.001$ ], respectively).

After accounting for confounding factors and interactions, the GEE analysis showed that the PC intervention was significantly related to a reduction in $\mathrm{HbA}_{1 \mathrm{c}}$ (Wald chi-square, 9.518; regression coefficient, $\mathrm{B},-0.486$ [95\% confidence interval (CI), -0.177 to -0.795 ]; $P=0.002$ ) and an increase in medication adherence (Wald chi-square, 6.694; odds ratio, $1.903 ;$ 95\% CI, 1.169-3.099; $P=0.010$ ).

\section{Discussion}

The findings of the study show that the PC model used has a positive effect on medication adherence and on the glycemic control (FBG and $\mathrm{HbA}_{1 \mathrm{c}}$ ) of people with T2DM. There was no significant difference at baseline in terms of demographic and medical data between the control and intervention groups.

The present study has about $10 \%$ more female than male participants (Table 1), but the Malaysian Third National 


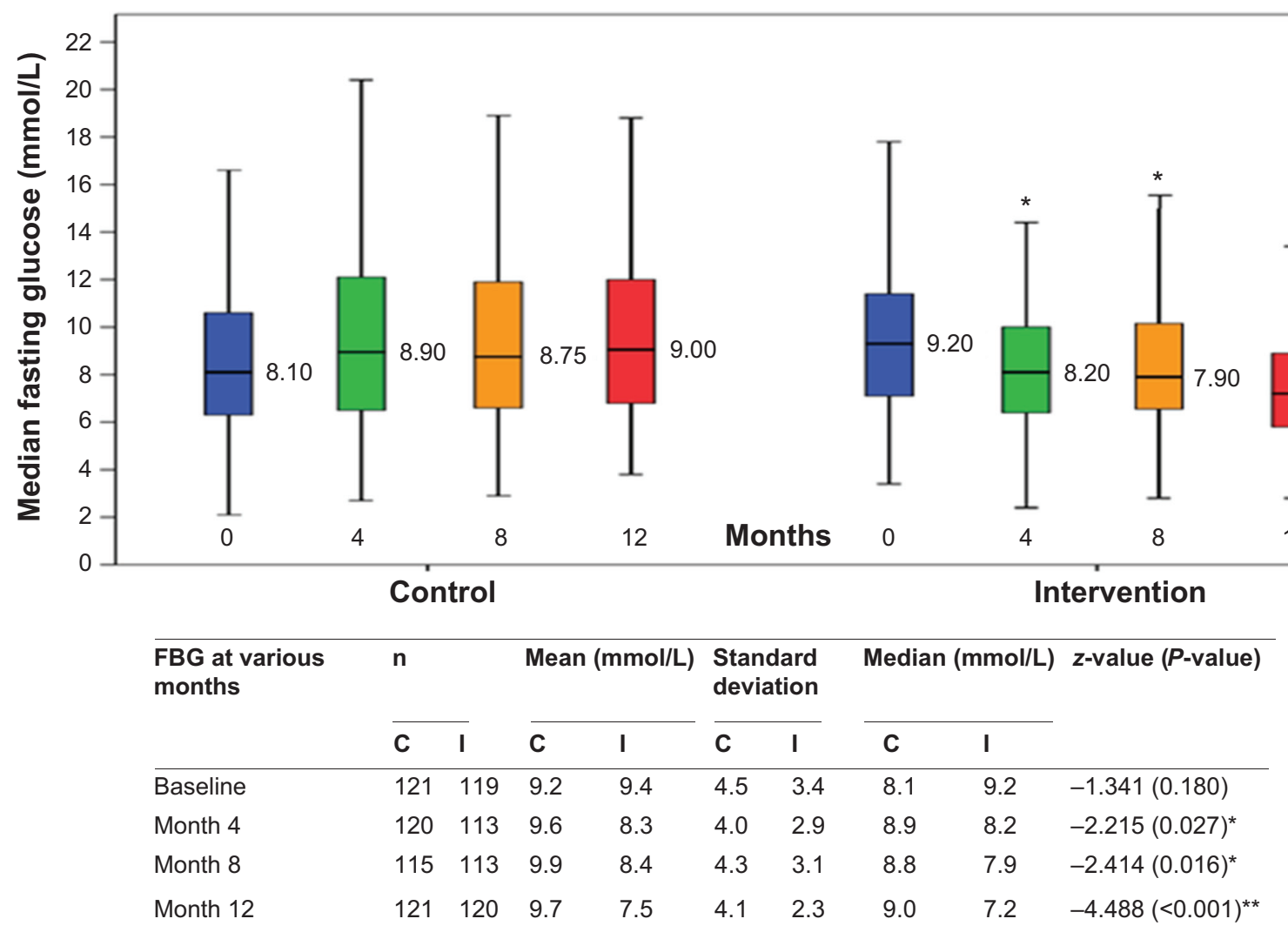

Figure I Comparison of FBG between control and intervention groups over time (shown as median in the graph).

Notes: $z$-value, Mann-Whitney $U$-test, *statistically significant at $P<0.05 ; * * P<0.01$.

Abbreviations: FBG, fasting blood glucose; C, control group; I, intervention group; n, number of participants in each group.

Health Morbidity Survey and the International Diabetes Federation have shown that the prevalence of T2DM in males was comparable with that in females..$^{1,2,43}$ The higher proportion of female participants may be because females with T2DM are more willing to participate in the study than males, as they are more likely to be nonworking housewives. The mean age of participants in this study is comparable with that in a previous study (59 versus 57.5 years old) ${ }^{44}$ The proportions of participants who are of Indian origin in this study is considered very high (33.5\%), as this ethnic group in Malaysia only constitutes about $10 \%$ of its population. This corresponds with other studies that found that the prevalence of T2DM is highest among people of Indian origin., ${ }^{2,43}$

The demographic and metabolic characteristics of the participants in this study are also similar to those obtained in the DiabCare Malaysia 2008 study. ${ }^{43}$ Approximately $25 \%$ of participants in the present study were overweight, whereas more than $50 \%$ were obese. This percentage is also comparable with that obtained from the DiabCare Malaysia 2008 study (mean BMI, $29 \mathrm{~kg} / \mathrm{m}^{2}$ versus $\left.27.8 \mathrm{~kg} / \mathrm{m}^{2}\right){ }^{43,44}$ The growing prevalence of obesity and overweight cases is closely linked to the upsurge in the number of diabetes cases. Approximately $90 \%$ of T2DM cases are attributed to being overweight. ${ }^{43,44}$ Therefore, counseling on lifestyle modification is essential in the management of diabetes.

At 4,8 , and 12 months after the provision of $\mathrm{PC}$ to the intervention group, there was significant association between the prevalence of medication adherence and whether the participants were in the intervention or control group (Tables 2 and 3). This implies that the provision of PC to the intervention group has improved medication adherence significantly.

The relationships among participants, health care providers, and social support are fundamental interpersonal factors that are closely related to medication adherence. ${ }^{3}$ In the present study, several consultations with the pharmacist enabled the development and establishment of a better patient-pharmacist professional relationship. These consultations increased the trust of the participants and hence may have contributed to improved medication adherence. Other studies also report that good communication between participants and health care providers leads to favorable and improved medication adherence among people with T2DM. ${ }^{45}$ 


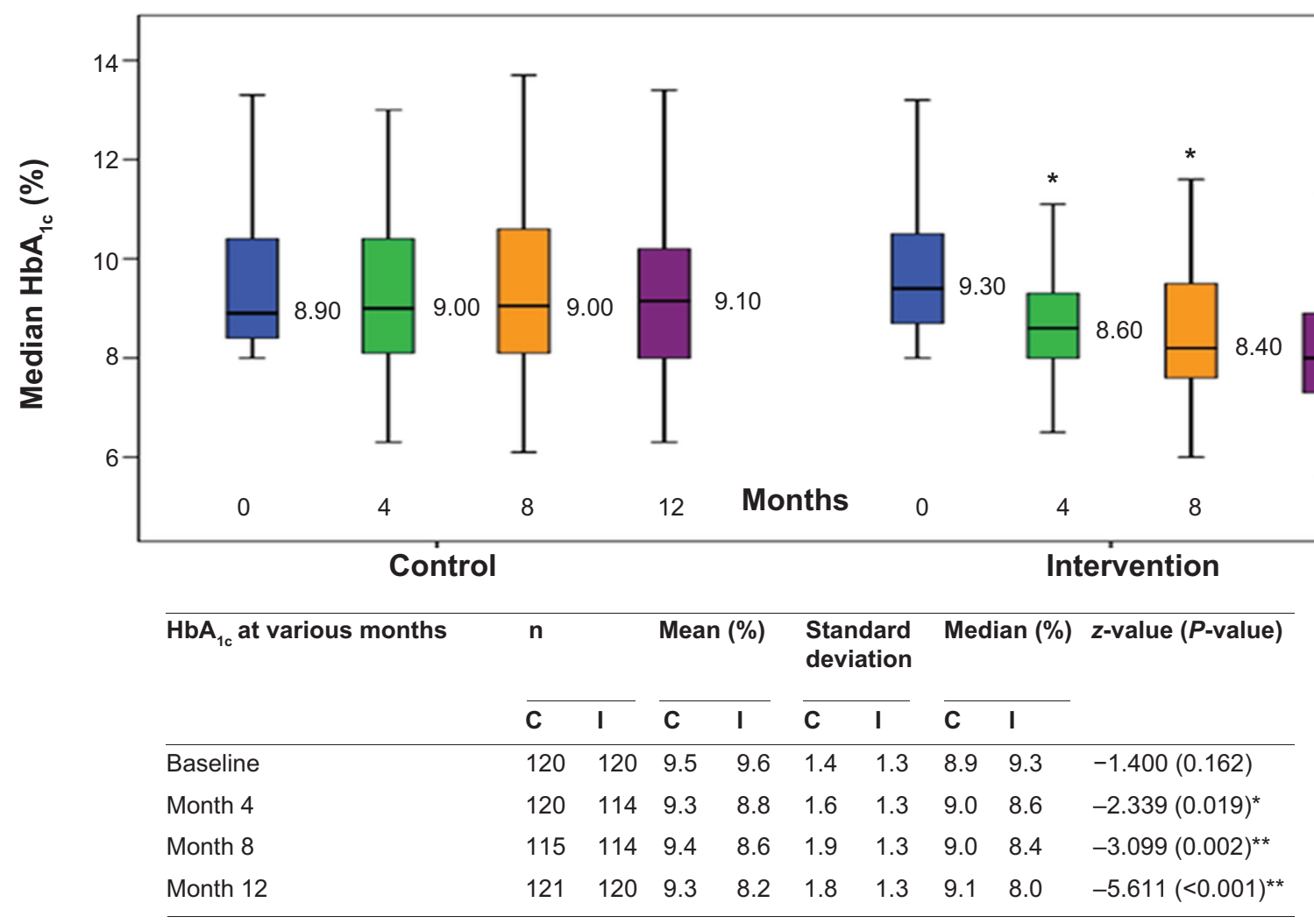

Figure 2 Comparison of $\mathrm{HbA}_{\mathrm{lc}}$ values between control and intervention groups over time (shown as median in the graph).

Notes: $z$-value, Mann-Whitney U-test, *statistically significant at $P<0.05 ; * * P<0.01$.

Abbreviations: $\mathrm{HbA}_{\mathrm{lc}}$, glycated hemoglobin; $\mathrm{C}$, control group; I, intervention group; n, number of participants in each group.

Participants in this study also had to manage complicated drug regimens, as more than $60 \%$ of the participants were receiving 6-10 medications. This increases the risk for an adverse event and/or a potential adherence issue. Therefore, continual assessment and surveillance by a pharmacist to identify and help these people resolve their drug-related

Table 3 Comparison of medication adherence between control and intervention groups when classified as nonadherence and adherence

\begin{tabular}{|c|c|c|c|}
\hline \multirow{2}{*}{$\begin{array}{l}\text { Adherencel } \\
\text { nonadherence }\end{array}$} & \multicolumn{2}{|c|}{ Frequency (\%) } & \multirow[t]{2}{*}{$\chi^{2}(P$-value $)$} \\
\hline & Control & Intervention & \\
\hline Baseline & $n=121$ & $n=120$ & $0.838(0.360)$ \\
\hline Nonadherence & 43 (35.0\%) & $36(30.0 \%)$ & \\
\hline Adherence & 78 (64.5\%) & 84 (70.0\%) & \\
\hline Month 4 & $n=109$ & $n=115$ & $7.15 \mathrm{I}(0.007)^{*}$ \\
\hline Nonadherence & 48 (44.0\%) & 31 (27.0\%) & \\
\hline Adherence & $6 \mathrm{I}(56.0 \%)$ & 84 (73.0\%) & \\
\hline Month 8 & $n=110$ & $\mathrm{n}=102$ & $7.118(0.008)^{*}$ \\
\hline Nonadherence & 46 (4I.8\%) & $25(24.5 \%)$ & \\
\hline Adherence & 64 (58.2\%) & 77 (75.5\%) & \\
\hline Month 12 & $n=121$ & $n=120$ & $7.238(0.007)^{*}$ \\
\hline Nonadherence & 50 (4I.3\%) & $30(25.0 \%)$ & \\
\hline Adherence & 71 (58.7\%) & 90 (75.0\%) & \\
\hline
\end{tabular}

Notes: $\chi^{2}$, chi-square test, *statistically significant at $P<0.01$. problems is essential for the successful management of diabetes.

Significant improvements in glycemic control were observed at 4 months after implementing the PC model, and this was sustained until the end of the study. These findings are similar to those of other studies conducted in other countries. ${ }^{46-49}$ This shows that the PC model used in this study was effective in improving the medication adherence and glycemic levels of patients with T2DM.

Nonetheless, the average mean values of $\mathrm{FBG}$ and $\mathrm{HbA}_{10}$ of the participants were still above the recommended target range at the end of the study period. This may be because of the high baseline values during the recruitment period (mean of control: FBG, $9.2 \mathrm{mmol} / \mathrm{L}$; $\mathrm{HbA}_{1 \mathrm{c}}, 9.5 \%$; intervention: FBG, $9.4 \mathrm{mmol} / \mathrm{L} ; \mathrm{HbA}_{1 \mathrm{c}}$, 9.6\%). However, the proportion of participants in the intervention group who achieved $\mathrm{HbA}_{1 \mathrm{c}}$ levels less than $8 \%$ at the end of the study period was significantly higher than that of the control group. In addition, the results showed that the intervention participants achieved a mean reduction in $\mathrm{HbA}_{1 \mathrm{c}}$ of $1.4 \%$ (going from 9.6\%-8.2\% at the end of the study period). Therefore, this reduction is considered clinically significant, and the PC model is deemed to be successful. 
Table 4 Comparison of fasting blood glucose and glycated hemoglobin $\left(\mathrm{HbA}_{\mathrm{lc}}\right)$ within control and intervention groups over the study period

\begin{tabular}{|c|c|c|c|c|}
\hline \multirow[t]{2}{*}{ Differences } & \multicolumn{2}{|c|}{ Fasting blood glucose (z-value ${ }^{\#}[P$-value $\left.]\right)$} & \multicolumn{2}{|c|}{$\underline{\text { HbA }_{\text {Ic }}(z \text {-value }}{ }^{\#}[P$-value $\left.]\right)$} \\
\hline & Control & Intervention & Control & Intervention \\
\hline Baseline -4 months & $-0.761(0.446)$ & $-3.968(<0.001)^{*}$ & $-1.780(0.075)$ & $-8.595(<0.001)^{*}$ \\
\hline Baseline- 8 months & $-1.45 \mathrm{I}(0.147)$ & $-2.784(0.005)^{*}$ & $-0.831(0.406)$ & $-7.157(<0.001)^{*}$ \\
\hline Baseline-12 months & $-1.134(0.257)$ & $-5.909(<0.00 \mathrm{I})^{*}$ & $-1.115(0.265)$ & $-8.265(<0.00 \mathrm{I})^{*}$ \\
\hline 4 months -8 months & $-0.109(0.913)$ & $-0.511(0.609)$ & $-0.823(0.41 \mathrm{I})$ & $-2.728(0.006)^{*}$ \\
\hline 4 months -12 months & $-0.008(0.994)$ & $-2.980(0.003)^{*}$ & $-0.554(0.580)$ & $-4.83 \mathrm{I}(<0.00 \mathrm{I}) *$ \\
\hline 8 months -12 months & $-0.268(0.788)$ & $-3.264(0.001)^{*}$ & $-0.159(0.874)$ & $-4.884(<0.001)^{*}$ \\
\hline
\end{tabular}

Notes: $Z$-value, Wilcoxon signed-rank test, *statistically significant at $P<0.0$ I.

Abbreviation: $\mathrm{HbA}_{\mathrm{Ic}}$, glycated hemoglobin.

For each $10 \%$ increase in adherence, $\mathrm{HbA}_{1 \mathrm{c}}$ decreased significantly by $0.14 \%-0.16 \%{ }^{50}$ However, in the present study, $\mathrm{HbA}_{1 \mathrm{c}}$ improved by $1.4 \%$, whereas the adherence levels improved by $5 \%$. Nonetheless, this indicates the importance of emphasizing medication adherence as part of a diabetes management program.

The GEE model shows that the PC intervention has a significant positive effect on $\mathrm{HbA}_{1 \mathrm{c}}$ values and on the medication adherence of people with T2DM. The odds of the intervention participants being adherent to their medications were almost double the odds for those who did not receive pharmaceutical care. This further confirms the importance of providing pharmaceutical care services as a component of diabetes management.

\section{Limitations of the study}

One of the limitations of this study was that it was conducted in English only. However, Malaysia is a multiracial society with three main ethnic groups: Malays, Chinese, and Indians. Therefore, the results may not be representative of T2DM patients who cannot communicate in English.

In addition, the study was conducted only in a single hospital, and hence the results could not be generalized to T2DM patients in other hospitals and in community pharmacy settings, although the demographic data of the participants corresponds with those of other studies. There may also be cross-contamination between participants in the control and intervention groups that could not be avoided, as they were attending the same clinic. Control participants may have discussed the study with the intervention participants and obtained some information regarding their disease conditions and medications. Therefore, the effects of the PC intervention may have been diluted. In addition, the implementation of this PC model on a wider scale may be limited by the health care infrastructure, as well as possibly cost and patients' access to health care facilities.
The participants were followed-up for only one year due to limited study time frame, which may not be adequate to detect long-term diabetes complications, and hence the long-term benefits of the PC model used in this study could not be determined.

\section{Conclusion}

The collaborative efforts between pharmacists and other health care professionals through the provision of PC, as demonstrated in this study, has positive effects on medication adherence and glycemic levels of people with T2DM. Therefore, the PC model used in this study should be duplicated in other health care settings for the benefit of more people with T2DM. Further studies can be conducted to evaluate the long-term effects of PC, as well as the cost-effectiveness of such services.

\section{Acknowledgments}

We acknowledge the University of Malaya for funding this project under grant PG 138-2012B. We also express our appreciation to Samihah Mat Junoh for her assistance in recruiting participants and data collection. We also thank Dr David Wu from Monash University Sunway Campus for his advice and assistance on statistical analysis, as well as Christopher Wilcox from the University of South Florida for his assistance in editing this manuscript. We are very grateful to all the study participants for their full cooperation during the data collection period and for their willingness to be in the study. In addition, we acknowledge the cooperation and assistance of all the staff in the Pharmacy Department and the Diabetes Clinic of the University Malaya Medical Centre.

\section{Author contributions}

WWC organized the study, collected the data, contributed to the discussion, and drafted the manuscript. SSC was involved in the design of the study, contributed to the discussion, and reviewed and edited the manuscript. PSML 
contributed to the discussion and reviewed and edited the manuscript. SPC provided clinical advice, contributed to the discussion, and reviewed and edited the manuscript. All authors checked the final version of the manuscript before submission.

\section{Disclosure}

The authors report no conflicts of interest in this work.

\section{References}

1. World Health Organization. Adherence to Long-term Therapies: Evidence for Action. Geneva: World Health Organization; 2003. Available from: http://www.who.int/chp/knowledge/publications/ adherence_report/en/. Accessed June 24, 2013.

2. International Diabetes Federation. IDF Diabetes Atlas. 6th ed. Available from: http://www.idf.org/sites/default/files/EN_6E_Atlas_Full_0.pdf. Accessed: June 15, 2013.

3. Letchuman GR, Wan Nazaimoon WM, Wan Mohamad WB, et al. Prevalence of diabetes in the Malaysian National Health Morbidity Survey III 2006. Med J Malaysia. 2010;65(3):173-179. Available from http:// www.e-mjm.org/2010/v65n3/Diabetes.pdf. Accessed August 11, 2014.

4. Mustapha F, Omar Z, Mihat O, et al. Addressing non-communicable diseases in Malaysia: an integrative process of systems and community. BMC Public Health. 2014;14(Suppl 2):S4.

5. Clifford RM, Davis WA, Batty KT, Davis TM; Fremantle Diabetes Study. Effect of a pharmaceutical care program on vascular risk factors in type 2 diabetes: the Fremantle Diabetes Study. Diabetes Care 2005;28(4):771-776.

6. Scain SF, Friedman R, Gross JL. A structured educational program improves metabolic control in patients with type 2 diabetes: a randomized controlled trial. Diabetes Educ. 2009;35(4):603-611.

7. American Diabetes Association. Diagnosis and classification of diabetes mellitus. Diabetes Care. 2013;36(Suppl 1):S67-S74.

8. Pladevall M, Williams LK, Potts LA, Divine G, Xi H, Lafata JE. Clinical outcomes and adherence to medications measured by claims data in patients with diabetes. Diabetes Care. 2004;27(12):2800-2805.

9. UK Prospective Diabetes Study Group. Tight blood pressure control and risk of macrovascular and microvascular complications in type 2 diabetes: UKPDS 38. BMJ. 1998;317(7160):703-713.

10. Zaini A. Where is Malaysia in the midst of the Asian epidemic of diabetes mellitus? Diabetes Res Clin Pract. 2000;50(Suppl 2):S23-S28.

11. Krass I, Taylor SJ, Smith C. CL. A. Impact on medication use and adherence of Australian pharmacists' diabetes care services. $J \mathrm{Am}$ Pharm Assoc. 2003;45(1):33-40.

12. Krass I, Hebing R, Mitchell B, et al. Diabetes management in an Australian primary care population. J Clin Pharm Ther. 2011;36(6): 664-672.

13. Martin LR, Williams SL, Haskard KB, Dimatteo MR. The challenge of patient adherence. Ther Clin Risk Manag. 2005;1(3):189-199.

14. Mehuys E, Van Bortel L, De Bolle L, et al. Effectiveness of a community pharmacist intervention in diabetes care: a randomized controlled trial. J Clin Pharm Ther. 2011;36(5):602-613.

15. Nichols-English G, Poirier S. Optimizing adherence to pharmaceutical care plans. J Am Pharm Assoc (Wash). 2000;40(4):475-485.

16. Horswell RL, Wascom CK, Cerise FP, et al. Diabetes mellitus medication assistance program: relationship of effectiveness to adherence. $J$ Health Care Poor Underserved. 2008;19(3):677-686.

17. Ahmad NS, Ramli A, Islahudin F, Paraidathathu T. Medication adherence in patients with type 2 diabetes mellitus treated at primary health clinics in Malaysia. Patient Prefer Adherence. 2013;7:525-530.

18. Chua SS, Chan SP. Medication adherence and achievement of glycaemic targets in ambulatory type 2 diabetic patients. J Appl Pharm Sci. 2011;1(4):55-59. Available from http://www.japsonline.com/admin/ php/uploads/60_pdf.pdf. Accessed August 11, 2014.
19. Tan MY, Magarey J. Self-care practices of Malaysian adults with diabetes and sub-optimal glycaemic control. Patient Educ Couns. 2008; 72(2):252-267.

20. Grant R, Adams AS, Trinacty CM, et al. Relationship between patient medication adherence and subsequent clinical inertia in type 2 diabetes glycemic management. Diabetes Care. 2007;30(4):807-812.

21. Sisson E, Kuhn C. Pharmacist roles in the management of patients with type 2 diabetes. J Am Pharm Assoc (2003). 2009;49(0)(Suppl 1): S41-S45.

22. Schapansky LM, Johnson JA. Pharmacists' attitudes toward diabetes. J Am Pharm Assoc (Wash). 2000;40(3):371-377.

23. Szumita PM. The hospital pharmacist: an integral part of the hyperglycaemic management team. J Clin Pharm Ther. 2009;34(6):613-621.

24. Lee P. Automation and the Future Practice of Pharmacy - Changing the Focus of Pharmacy. In: Wilson AL, editor. Issues in Pharmacy Practice Management United States of America. Gaithersburg, MD: Aspen Publishers, Inc; 1997:79-91.

25. Hepler CD, Strand LM. Opportunities and responsibilities in pharmaceutical care. Am J Hosp Pharm. 1990;47(3):533-543.

26. Gold R, Yu K, Liang L-J, et al. Synchronous provider visit and self-management education improves glycemic control in Hispanic patients with long-standing type 2 diabetes. Diabetes Educ. 2008;34(6): 990-995.

27. Howteerakul N, Suwannapong N, Rittichu C, Rawdaree P. Adherence to regimens and glycemic control of patients with type 2 diabetes attending a tertiary hospital clinic. Asia Pac J Public Health. 2007; 19(1):43-49.

28. Jaber LA, Halapy H, Fernet M, Tummalapalli S, Diwakaran H. Evaluation of a pharmaceutical care model on diabetes management. Ann Pharmacother. 1996;30(3):238-243.

29. Campbell RK. Role of the pharmacist in diabetes management. $A m$ $J$ Health Syst Pharm. 2002;59(Suppl 9):S18-S21.

30. Murray MD, Young J, Hoke S, et al. Pharmacist intervention to improve medication adherence in heart failure: a randomized trial. Ann Intern Med. 2007;146(10):714-725.

31. Scott JC, Conner DA, Venohr I, et al. Effectiveness of a group outpatient visit model for chronically ill older health maintenance organization members: a 2-year randomized trial of the cooperative health care clinic. J Am Geriatr Soc. 2004;52(9):1463-1470.

32. Wermeille J, Bennie M, Brown I, McKnight J. Pharmaceutical care model for patients with type 2 diabetes: integration of the community pharmacist into the diabetes team - a pilot study. Pharm World Sci. 2004;26(1):18-25.

33. Krass I, Armour CL, Mitchell B, et al. The Pharmacy Diabetes Care Program: assessment of a community pharmacy diabetes service model in Australia. Diabet Med. 2007;24(6):677-683.

34. Krass I, Mitchell B, Song YJ, et al. Diabetes Medication Assistance Service Stage 1: impact and sustainability of glycaemic and lipids control in patients with Type 2 diabetes. Diabet Med. 2011;28(8):987-993.

35. Al-Qazaz HK, Hassali MA, Shafie AA, Syed Sulaiman SA, Sundram S. Perception and knowledge of patients with type 2 diabetes in Malaysia about their disease and medication: a qualitative study. Res Social Adm Pharm. 2011;7(2):180-191.

36. Chua SS, Lai PSM, Tan CH, Chan SP, Chung WW, Morisky DE. The development and validation of the Malaysian medication adherence scale (MALMAS) among patients with 2 type diabetes in Malaysia. Int $J$ Pharm Pharm Sci. 2013;5(3):790-794. Available from http://www. ijppsjournal.com/Vol5Issue3/7175.pdf. Accessed August 11, 2014.

37. Morisky DE, Ang A, Krousel-Wood M, Ward HJ. Predictive validity of a medication adherence measure in an outpatient setting. $J$ Clin Hypertens (Greenwich). 2008;10(5):348-354.

38. Södergård $\mathrm{B}$, Halvarsson $\mathrm{M}$, Tully $\mathrm{MP}$, et al. Adherence to treatment in Swedish HIV-infected patients. J Clin Pharm Ther. 2006; 31(6):605-616.

39. Centers for Disease Control and Prevention. 2011 National Diabetes Fact Sheet. Available from: http://www.cdc.gov/diabetes/pubs/factsheet11.htm. Accessed June 24, 2013. 
40. Stratton IM, Adler AI, Neil HA, et al. Association of glycaemia with macrovascular and microvascular complications of type 2 diabetes (UKPDS 35): prospective observational study. BMJ. 2000; 321(7258):405-412.

41. Jabatan Perangkaan Malaysia. Findings of the Household Income Survey (HIS) 2012. 2012. Available from: http://www.statistics.gov.my/ portal/images/stories/files/LatestReleases/household/HIS_2012_Eng. pdf. Accessed May 20, 2014.

42. Expert Consultation WHO; WHO Expert Consultation. Appropriate body-mass index for Asian populations and its implications for policy and intervention strategies. Lancet. 2004;363(9403):157-163.

43. Mafauzy M, Hussein Z, Chan SP. The status of diabetes control in Malaysia: results of DiabCare 2008. Med J Malaysia. 2011;66(3): 175-181.

44. Hossain P, Kawar B, El Nahas M. Obesity and diabetes in the developing world - a growing challenge. $N$ Engl J Med. 2007;356(3):213-215.

45. Jin J, Sklar GE, Min Sen Oh V, Chuen Li S. Factors affecting therapeutic compliance: A review from the patient's perspective. Ther Clin Risk Manag. 2008;4(1):269-286.
46. Rhee MK, Slocum W, Ziemer DC, et al. Patient adherence improves glycemic control. Diabetes Educ. 2005;31(2):240-250.

47. Al-Qazaz HK, Sulaiman SA, Hassali MA, et al. Diabetes knowledge, medication adherence and glycemic control among patients with type 2 diabetes. Int J Clin Pharmacol. 2011;33(6):1028-1035.

48. Mayberry LS, Osborn CY. Family support, medication adherence, and glycemic control among adults with type 2 diabetes. Diabetes Care. 2012;35(6):1239-1245.

49. Rausch JR, Hood KK, Delamater A, et al. Changes in treatment adherence and glycemic control during the transition to adolescence in type 1 diabetes. Diabetes Care. 2012;35(6):1219-1224.

50. $\mathrm{Hu} \mathrm{FB}$, Manson JE, Stampfer MJ, et al. Diet, lifestyle, and the risk of type 2 diabetes mellitus in women. $N$ Engl J Med. 2001;345(11): 790-797.

\section{Publish your work in this journal}

Patient Preference and Adherence is an international, peer-reviewed, open access journal that focuses on the growing importance of patient preference and adherence throughout the therapeutic continuum. Patient satisfaction, acceptability, quality of life, compliance, persistence and their role in developing new therapeutic modalities and compounds to optimize clinical outcomes for existing disease states are major areas of interest for the journal. This journal has been accepted for indexing on PubMed Central. The manuscript management system is completely online and includes a very quick and fair peer-review system, which is all easy to use. Visit http://www dovepress.com/testimonials.php to read real quotes from published authors.

Submit your manuscript here: http://www.dovepress.com/patient-preference-and-adherence-journal 